\title{
Continuing medical education for the trained physician. Recommendations for the introduction and implementa- tion of a CME system
}

\author{
A report by the Royal Colleges of Physicians of Edinburgh, Glasgow and London, June 1994
}

\section{Peter Wilkinson}

Chairman - National Association of Clinical Tutors, 12 Chandos Street, London WIM 9DE, UK.

The trend to ensure that doctors keep up to date with changes in medical practice and other aspects of their professional lives has recently gathered pace with physicians in the UK joining their counterparts in Australia and the United States in having a system which documents and encourages continuing medical education (CME). Professions such as the law and architecture already have systems in place and, in the summer of last year, the Conference of Medical Royal Colleges and their Faculties agreed on some principles to support formal CME programmes. This publication by the Colleges of Physicians in the UK is part of that process and shows a welcome collaboration between the three Colleges in forming a consensus on this important issue rather than bringing out their own separate documents.

How do the physicians envisage their system working? In brief they expect every practising physician to achieve an average of 100 hours of CME each year over a 5 yearly cycle, of which $50 \%$ must be external to the unit in courses and meetings approved by the College. The document sketches out the kind of activities that it expects to be included in CME programmes and outlines the responsibilities at each level of the system moving from the individual to the various organizations that will be involved.

The majority of physicians will comfortably exceed the suggested requirements, apart from the difficult question of external CME. Previous reports by Standing Committee on Postgraduate Medical Education (SCOPME) have suggested that most consultants take less then half of their study leave allocation (at present 10 working days) and making 10 days of external CME mandatory will create distinct tensions.

Introducing more time away from the unit in a health care system that is already experiencing considerable signs of strain will create a demand for more staff in the hospital sector when funds are being taken away from it and put into primary care. Some may also question the value of making doctors take half of their CME requirements away from the unit. There is a risk that some will go to meetings funded by the pharmaceutical industry with their own agenda and attend passive meetings rather than being required to construct and actively participate in education at their own hospital or between groups of local hospitals. This has been the experience in the USA and developments will have to be watched carefully over here. There is also a concern that, to use the present jargon, the Colleges are going to be both purchasers and providers of external educational courses at a time when the split between these two functions is meant to become clearer.

When regulating the new system, the Colleges have plumped for the simplicity of counting hours? rather than the complexity of trying to weighte various educational activities. In the preface they pose the following question 'After all, how does one compare giving a lecture with attending the same lecture?'. The answer is that giving and preparing a lecture is of considerably greater educational benefit to the individual than listening to it in a darkened lecture theatre. It is probably correct to go for the simplest system first, but I hope that further work could be carried out over the next few years to see if a weighting system would add value and not be unnecessarily complex. A recent meta-analysis of CME has shown that educational activities can be effective but only under certain circumstances, such as when they actively involve the participants, seek views on their educational needs and provide feedback with the assessment.

Lastly, the Colleges have come out against a mandatory system of CME, but will use the power and influence they have to persuade their members in various ways to achieve the necessary points rather than force them to do so.

This document is to be welcomed as a starting point on the road to ensure that all medical practitioners attend an appropriate number and range of CME activities. It does not ensure competence in practice but, if the programmes are properly constructed, it provides a starting point to ensure that doctors keep updated in their professional careers. 